\title{
CONSTITUCIÓN Y DISLOCACIÓN: EL GIRO LINGÜÍSTICO EN JACQUES DERRIDA
}

\author{
JOSÉ LUIS LÓPEZ DE LIZAGA \\ Universidad de Zaragoza
}

\begin{abstract}
RESUMEN: Este artículo examina los argumentos de Jacques Derrida contra la fenomenología de Husserl y a favor de la tesis principal del giro lingüístico: la tesis de que no hay pensamiento sin lenguaje. A continuación se defiende que la disolución derridiana de la subjetividad en el lenguaje no es la consecuencia de afirmar el giro lingüístico como tal, sino del modelo de lenguaje que adopta y radicaliza Derrida: el modelo estructuralista de Ferdinand de Saussure. Finalmente, partiendo de las objeciones de Ricoeur se argumenta que la omisión de la dimensión pragmática del lenguaje (el habla) es la raíz de las principales paradojas de la filosofía postestructuralista de Derrida en la teoría del significado, la referencia y la subjetividad.
\end{abstract}

PALABRAS CLAVE: giro lingüístico; postestructuralismo; signo; subjetividad.

\section{Constitution and Dislocation: Jacques Derrida and the Linguistic Turn}

ABSTRACT: This paper analyzes Jacques Derrida's arguments against Husserl's phenomenology and in support of the main thesis of the linguistic turn, namely: there is no possible thinking without language. Next the paper shows that Derrida's dissolution of subjectivity in language is not a consequence of the linguistic turn as such, but of Saussure's structuralist language model which Derrida adopts and radicalizes. Finally, following some arguments of Ricoeur the paper states that the omission of the pragmatic dimension of language is the main root of Derrida's paradoxical theses about meaning, reference and subjectivity.

KEY WORDS: linguistic turn; poststructuralism; sign; subjectivity.

Las tres variantes del giro lingüístico de la filosofía del siglo XX —analítica, hermenéutica y estructuralista- compartieron una tesis básica: no hay pensamiento sin lenguaje o, por decirlo en palabras de Ch. S. Peirce, «no tenemos ninguna facultad de pensar sin signos» ${ }^{1}$. Pero el consenso en torno a ella parece haber sido meramente nominal, porque tan pronto como se examina su significado y sus consecuencias en cada una de estas corrientes, aparecen diferencias profundas: para algunos filósofos el lenguaje es aquello que posibilita nuestra experiencia del mundo y de nosotros mismos, mientras que, para otros, el lenguaje más bien socava ambas experiencias al filtrarlas o tamizarlas de un modo irremediablemente distorsionador. Cabe atribuir el primer punto de vista a la tradición analítica del giro lingüístico (representada por Wittgenstein o Tugendhat), mientras que la segunda perspectiva corresponde más bien al estructuralismo (Saussure, Lévi-Strauss) y todavía más a su continuación postestructuralista (Foucault, Derrida), cuyos representantes elaboraron

1 Peirce, Ch. S., Obra lógico-semiótica, Taurus, Madrid, 1987, p. 60. 
la paradójica y archifamosa idea de la «muerte del sujeto» o la «muerte del hombre»².

¿Cuál de estas dos posiciones acerca de la relación entre el lenguaje y la subjetividad es más verosímil? Me inclino a pensar que el enfoque desarrollado por la filosofía analítica es más plausible, y para mostrarlo de manera indirecta quisiera estudiar en las páginas que siguen la que quizás sea la versión más radical del giro lingüístico postestructuralista: la que propone Jacques Derrida. Este autor defiende consecuentemente una posición muy paradójica, que cabe resumir así: contra lo que pretendió la tradición de la filosofía de la conciencia (cuyo último gran representante sería Husserl), la subjetividad y la autoconciencia son fenómenos indisociables del lenguaje; pero el lenguaje, al tiempo que hace posibles los fenómenos subjetivos, los distorsiona e incluso cabe decir que los vuelve imposibles. Por emplear dos términos que emplea el propio Derrida: el lenguaje "constituye y simultáneamente disloca» al sujeto ${ }^{3}$. Cabría objetar que esta posición no es solo paradójica, sino probablemente aporética e insostenible, pues ¿cómo puede afirmarse que un fenómeno está constituido por algo que, al mismo tiempo, lo imposibilita? Solo tiene sentido decir que algo está «dislocado» si se lo compara con una versión original, libre de distorsiones, pues sin esa comparación no sería reconocible la dislocación como tal. Pero aquí no nos interesaremos tanto por las conclusiones aporéticas a las que quizás conduce el planteamiento derridiano, cuanto por las premisas de las que parte su argumentación. Intentaremos mostrar que la dislocación de la subjetividad no se debe a su constitución lingüística como tal, que Derrida defiende de un modo muy inteligente en sus escritos sobre Husserl convergiendo en varios puntos esenciales con Wittgenstein y la filosofía analítica (I). La dislocación de la subjetividad se debe más bien a un determinado modelo de lenguaje, que Derrida asume y afina hasta las últimas consecuencias: el del estructuralismo de Ferdinand de Saussure (II). A partir de algunos argumentos de Paul Ricoeur, mostraremos que ese modelo está lastrado desde el principio por la omisión de la dimensión pragmática del lenguaje: la abstracción metódica del habla parece ser, en efecto, la raíz de las principales paradojas de la filosofía postestructuralista de Derrida en la explicación del significado, la referencia y la subjetividad (III).

En una controversia filosófica las críticas más eficaces, las más contundentes, no son aquellas que se enfrentan a una teoría desde una posición

2 La tercera versión del giro lingüístico, la hermenéutica, es más ambigua en este punto, puesto que acoge a filósofos como Heidegger, que redujo al sujeto a un mero vehículo de un acontecer lingüístico impersonal, pero también a otros que - como Apel, Habermas o Ricoeur- conciben el lenguaje como el elemento que constituye la conciencia y la autoconciencia, en lugar de disolverlas.

3 Derrida, J., De la gramatología, Siglo XXI, México, 1971, p. 89. 
completamente exterior a ella, sino más bien las que señalan sus inconsistencias internas, sobre todo cuando esas inconsistencias sugieren que la teoría criticada da implícitamente la razón a alguna otra teoría rival. De este estilo es la crítica de Derrida a la fenomenología de Husserl, y en concreto a su concepción de la relación entre la conciencia y el lenguaje, o más exactamente: entre una presunta experiencia prelingüística y su expresión lingüística.

En la primera de las Investigaciones lógicas, Husserl propone una teoría del significado según la cual los signos lingüísticos obtienen su significado de las intenciones o «actos de significación» del sujeto que los emplea. Éste es el rasgo que distingue las expresiones, en tanto que signos propiamente lingüísticos, de otros signos como las señales (huellas, indicios, etc.), en las que algo indica para alguien la existencia de alguna otra cosa por un vínculo asociativo. Por ejemplo, al percibir una columna de humo, el observador infiere la existencia de una hoguera próxima, pero no diríamos que la columna de humo significa el humo como lo hace la palabra «humo». En el primer caso tenemos una señal, y en el segundo una expresión. Pero para comprender en qué consisten las expresiones no basta con distinguir el signo físico - hablado o escrito- de los actos mentales que le dan sentido, pues aún es necesario diferenciar cuidadosamente estos actos de otros elementos asimismo presentes en los fenómenos lingüísticos. Inspirándose en los trabajos de Frege, Husserl distingue al menos cuatro elementos en la descripción fenomenológica de las expresiones lingüísticas: [1] una parte física (los signos hablados o escritos), [2] las vivencias o actos psíquicos que dan sentido a la expresión (el acto de significación) ${ }^{4}$, [3] las representaciones mentales (las imágenes de la fantasía) asociadas subjetivamente a la expresión, y por último [4] el objeto al que la expresión se refiere, que ni se identifica con las imágenes de la fantasía, ni se confunde con el significado del signo. Las palabras que componen la expresión «el vencedor de Jena» solo tienen significado para la conciencia que reconoce en ellas una denominación de Napoleón. Ni las letras ni el acto mental que les confiere sentido o lo reconoce

4 Cf. Husserl, E., Investigaciones lógicas, Alianza, Madrid, 1999, vol. 1, p. 239. El «acto de significación» es la instanciación temporal de un significado intemporal. Conviene recordar esto para no malinterpretar el pensamiento de Husserl. Así, por ejemplo, Michael Dummett ve en la teoría de Husserl una teoría intencionalista, según la cual el significado de las expresiones se identifica con la intención significativa del hablante. Dummett caricaturiza las teorías de este tipo como "teorías de Humpty-Dumpty», en honor del conocido personaje de Lewis Carroll que afirmaba lo siguiente: "Cuando yo uso una palabra quiere decir lo que yo quiero que diga..., ni más ni menos». (Dummetт, M., Origins of Analytical Philosophy, Harvard UP, Cambridge (Mass.), 1996, cap. 6). Independientemente de si esta caricatura hace justicia a las teorías intencionalistas, lo cierto es que la posición de Husserl no puede inscribirse exactamente en esa categoría. Husserl distingue entre el acto de significación y el significado objetivo de la expresión, y sostiene que entre ambos se da una relación de ejemplarización o instanciación: mi pensamiento de que $2+2=4$ es una instancia de la proposición ideal « $2+2=4$ ». Por consiguiente, la posición de Husserl es más bien una combinación de intencionalismo y objetivismo platónico. Cf. sobre esto Simons, P., «Meaning and Language», en: Sмiтн, B. y Sмiтн, D. W., The Cambridge Companion to Husserl, Cambridge UP, Cambridge, pp. 108-115. 
en ellas son idénticas a Napoleón, es decir, al individuo real que vivió con ese nombre a finales del siglo XVIII y principios del XIX. Y ninguno de estos tres elementos, especialmente el acto mental de significación, debe confundirse con la imagen mental que cada hablante se forma cuando escucha o pronuncia el nombre Napoleón. El significado de una expresión lingüística no es nunca una imagen mental: «las imágenes concomitantes de la fantasía pertenecen más bien a los elementos no esenciales de la expresión» ${ }^{5}$.

Uno de los objetivos de Husserl en las Investigaciones lógicas es defender, contra el empirismo, que los significados lógico-lingüísticos tienen un estatuto ontológico objetivo, casi platónico. Para este fin resulta especialmente importante distinguir nítidamente el significado de una expresión y la «imagen mental concomitante», es decir, los elementos [2] y [3] de nuestra enumeración anterior. $\mathrm{Y}$ en efecto, Husserl apoya esta distinción con varios argumentos contundentes. ${ }^{6}$ En cambio, Husserl no prestó tanta atención a la relación entre el acto de significación y el elemento lingüístico en que encuentra su expresión (y en el que debemos incluir no solo el elemento [1] de nuestra enumeración, sino también las reglas y convenciones del lenguaje, en las que Husserl no repara). Las Investigaciones Lógicas parecen suponer simplemente que hay aquí dos dimensiones superpuestas, pero nítidamente separadas. Es interesante a este respecto el pasaje final de las consideraciones conducentes a distinguir los significados y las imágenes mentales. Husserl se pregunta si, una vez eliminadas dichas imágenes como candidatas a constituir el significado de las expresiones, no podríamos quedarnos simplemente con las expresiones mismas, con los signos, y prescindir así de los actos de los que depende supuestamente el significado. Observemos que esta hipótesis equivaldría a reducir el pensamiento al signo, y como mínimo nos aproximaría bastante a la tesis fundamental del giro lingüístico: se afirmaría, en tal caso, que puede haber pensamiento sin imágenes mentales, pero no sin signos (y eso es exactamente lo que afirmaba Peirce). Pero Husserl rechaza enérgicamente esta posición. La expresión lingüística y la significación mental son dos dimensiones igualmente irreductibles de los fenómenos lingüísticos, y la segunda ocupa incluso una posición superior a la primera, puesto que sin ella los signos no serían nada más que letra muerta:

\footnotetext{
5 Husserl, E., Investigaciones lógicas, op. cit., p. 255.

6 Las imágenes mentales cambian (podemos imaginar de muy distintas formas a Napoleón), mientras que la significación de la expresión «Napoleón» sigue siendo la misma (ibíd., p. 260). Además, podemos seguir comprendiendo el significado de la expresión cuando esas imágenes han desaparecido (ibíd., p. 260-261). Y a menudo sucede que no acertamos a imaginar nada cuando pensamos o hablamos sobre algún objeto, pero eso no impide que las expresiones referidas a ese objeto tengan pleno sentido. Ya Descartes utilizó en las $\mathrm{Me}$ ditaciones el ejemplo del quiliágono para probar esto mismo: entendemos perfectamente a qué nos referimos cuando hablamos de una figura geométrica de mil lados, pero la imagen que podemos formarnos de ella es completamente vaga, e indiscernible de, por ejemplo, la imagen de la figura de 1.002 lados o de la de 995 (ibíd., p. 261).
} 
(...) Estamos bien lejos de identificar la palabra y el pensamiento. Nosotros no creemos de ninguna manera que, cuando comprendemos símbolos sin el apoyo de imágenes concomitantes, exista el símbolo solo; ahí está además la comprensión, vivencia de un acto peculiar, que se refiere a la expresión, dándole luz, prestándole significación y con ella referencia objetiva? ${ }^{7}$.

La conciencia prelingüística y su expresión lingüística discurren, al parecer, en paralelo. Pero esta aproblemática relación de yuxtaposición o superposición entre el significante lingüístico y el significado mental revela una mayor complejidad cuando Husserl la somete a una reflexión más detenida en los parágrafos 124 a 127 de Ideas I. Derrida ve en estas pocas pero decisivas páginas la explicitación de una dificultad fundamental que el proyecto mismo de la fenomenología arrastraba desde las Investigaciones lógicas sin que Husserl pareciera haberla comprendido plenamente ${ }^{8}$. En Ideas $I$, Husserl distingue de nuevo dos «capas» o estratos de la experiencia expresada lingüísticamente: la capa de los «actos de expresión ${ }^{9}$ y el estrato más fundamental de los actos intencionales prelingüísticos. Pero Derrida observa ahora cierta vacilación en Husserl. Por un lado, Ideas I mantiene el punto de vista de Investigaciones lógicas, según el cual los actos que pertenecen al estrato básico pueden realizarse con entera independencia del lenguaje, de modo que éste no haría otra cosa que manifestar una intención prelingüística, "sacar afuera un sentido constituido sin él» ${ }^{10}$. Así sucede, por ejemplo, con nuestra percepción de un objeto blanco, a la que se superpone de algún modo la manifestación lingüística correspondiente (ya sea ésta pronunciada realmente, o ya la piense el sujeto solo para sí mismo):

Este proceso [perceptivo] no requiere lo más mínimo de una «expresión» (...) ni de nada semejante a un significar de las palabras (...). Pero si hemos "pensado» o enunciado que «esto es blanco», está a la vez ahí una nueva capa, a una con lo mentado en cuanto tal en forma puramente perceptiva ${ }^{11}$.

Y sin embargo, por otro lado aparece por primera vez la sospecha de que la relación entre las dos capas o estratos no es una relación de mera superposición, sino más bien un entrelazamiento o entretejimiento que no deja intacto a ninguno de los dos componentes: «el estrato lingüístico -interpreta Derridase entremezcla con el estrato prelingüístico» ${ }^{12}$. De ahí que Husserl desconfíe ahora de la metáfora que venía utilizando desde las Investigaciones lógicas para referirse a la relación de lenguaje y pensamiento:

A esta imagen de unas capas no hay que exigirle demasiado, no siendo la expresión algo así como un barniz que recubra o un traje que revista; es una

7 Ibíd., p. 262.

8 DeRrida, J., «La forma y el querer-decir», en: Márgenes de la filosofía, Cátedra, Madrid, 1989, pp. 193 y sigs.

9 Husserl, E., Ideas I, FCE, México, 1993, p. 295.

10 Derrida, J., Márgenes de la filosofía, op. cit., p. 201.

11 Husserl, E., Ideas I, op. cit., p. 296.

12 Derrida, J., Márgenes de la filosofía, op. cit., p. 199. 
conformación por el espíritu que ejerce sobre el estrato inferior nuevas funciones intencionales y experimenta correlativamente por parte de ella otras funciones intencionales ${ }^{13}$.

Husserl no extrae todas las consecuencias que para Derrida se siguen necesariamente de este segundo enfoque. Y es que no se trata aquí de un mero cambio de metáforas, de la inocua sustitución de la imagen de la superposición por la del entretejimiento. Al contrario, la sospecha de que el lenguaje podría estar entretejido con el sustrato de nuestros estados mentales intencionales obliga a revisar, y en el fondo a rechazar, la distinción misma entre ambos estratos. Ésa es, al menos, la conclusión que Derrida cree poder extraer de las vacilaciones de Husserl: «¿No se convierte en problemática a partir de este momento la idea misma de un lenguaje expresivo? ¿Y con ella la posibilidad de una distinción entre el estrato del sentido y el estrato del querer decir?» ${ }^{14} \mathrm{Si}$ el lenguaje se infiltra hasta el estrato inferior, en realidad no cabe hablar de un estrato de estados mentales intencionales que luego se reviste de una expresión lingüística, sino que resulta al menos igual de plausible la hipótesis de que la forma de la expresión lingüística prefigura o condiciona toda experiencia: «el orden sistemático del querer decir impone de alguna manera su sentido al sentido, le dicta su forma, le obliga a imprimirse según tal o cual regla, sintáctica u otra» ${ }^{15}$. O por decirlo una vez más con Peirce: también Husserl parece sospechar, al menos en estos pasajes de Ideas $I$, que no hay pensamiento sin signos.

Si es correcta la interpretación de Derrida, el propio Husserl se habría quedado a las puertas del giro lingüístico. Pero se detiene ahí, y no llega a dar el paso decisivo. ¿Por qué no lo hace? En La voz y el fenómeno, Derrida propone una brillante explicación para ello. Husserl habría pasado por alto que el pensamiento - que él llama, con una expresión muchas veces citada, la «vida solitaria del alma»-, es sin duda un proceso silencioso, pero no es un proceso asemiótico, porque cuando pensamos, y aunque no expresemos en voz alta o por escrito nuestros pensamientos, no hacemos otra cosa que hablar en silencio con nosotros mismos. La conciencia que piensa es una interiorización de la voz, y no existiría sin ésta: «(...) ninguna conciencia es posible sin la voz (...). La voz es la conciencia ${ }^{16}$. Pero Husserl habría obviado esta mediación lingüística de la conciencia dejándose engañar por una peculiaridad de la voz que la hace muy diferente de cualquier otro medio expresivo: su extrema proximidad al sujeto que la emite. En efecto, en condiciones normales el hablante se escucha a sí mismo hablar en el mismo instante en que emite sus palabras, y del mismo modo es consciente de su propio discurso silencioso en el instante en que está pensando:

13 Husserl, E., Ideas I, op. cit., p. 299.

14 Derrida, J., Márgenes de la filosofía, op. cit., p.211.

15 Ibíd., p. 204.

16 Derrida, J., La voix et le phénomène, PUF, Paris, 2009, p. 89. 
Esta presencia a sí del acto animador en la espiritualidad transparente de aquello que anima, esta intimidad de la vida consigo misma, eso que siempre ha hecho decir que la palabra está viva, todo ello supone, pues, que el sujeto que habla se escucha en el presente. Tal es la esencia o la normalidad del habla ${ }^{17}$.

La identidad que se verifica aquí entre el sujeto que habla y el que escucha, entre el sujeto y el objeto de la conciencia de sí, es más clara incluso que la que se nos da cuando percibimos nuestro propio cuerpo mediante la vista o el tacto. Yo puedo equivocarme en la identificación visual o incluso táctil de mi propio cuerpo $^{18}$, pero es mucho más difícil imaginar una situación en la que escuchase mi propia voz sin saber que es la mía, y desde luego parece completamente imposible un error de identificación de mi propio discurso interior, de mi propio pensamiento o conciencia, salvo en el caso de padecer alguna psicopatología. Esta infalibilidad parece relacionarse con el hecho de que en el fenómeno de escucharse a sí mismo al hablar se reduce al mínimo la distancia espacial entre sujeto y objeto que todavía media en la percepción táctil o visual, y que desaparece del todo en el discurso interior. Pero esta «reducción absoluta del espacio ${ }^{19}$, la circunstancia de que se esfume la distancia entre la voz y la escucha cuando nos oímos hablar a nosotros mismos, no elimina la mediación de esa otra forma de exterioridad que son los signos, el lenguaje. Y lo cierto es que no hay ninguna razón para pensar que la voz interior en que consiste el pensamiento prescinda de signos en mayor medida que la voz exterior, audible, que empleamos para comunicarnos con otros.

Por eso resultan desconcertantes las consideraciones de la primera de las Investigaciones lógicas acerca de la relación entre nuestra voz interior y nuestra voz exterior, audible. Husserl aprovecha la distinción entre expresión y señal, con la que comienza su investigación y a la que hemos hecho referencia páginas atrás, para caracterizar la diferencia entre el uso comunicativo del lenguaje y su uso aislado, no comunicativo, en el pensamiento solitario. En el lenguaje hablado las palabras son a la vez expresiones y señales: expresan un significado y señalan o indican al oyente la existencia de ciertas vivencias interiores del hablante, accesibles únicamente a éste. Así, por ejemplo, la proposición «Llueve»

17 Ibíd., p. 87. Las vacilaciones de Husserl se explican también por las importantes implicaciones de este asunto para todo su proyecto filosófico, puesto que la fenomenología aspira a fundar todo el conocimiento en un estrato de experiencia no distorsionada por ninguna interferencia, tampoco la de los signos. Cf. Derrida, J., Márgenes de la filosofía, op. cit., p. 199: «si un suelo intuitivo y perceptivo, un pedestal de silencio, no fundamenta el discurso en la presencia originariamente dada de la cosa misma (...), la descripción fenomenológica habrá fracasado».

18 Derrida, J., La voix et le phénomène, op. cit., p. 88. Manfred Frank cita como ejemplo de error en la identificación visual de sí mismo una anécdota referida por Ernst Mach. Al subir a un tranvía reparó en el aspecto más bien lamentable de un hombre que subía a la vez que él. Tardó unos instantes en darse cuenta de que ese hombre era él mismo, reflejado en un espejo. Cf. Frank, M., Selbstbewusstsein und Selbsterkenntnis, Reclam, Stuttgart, 1991, p. 286.

19 Derrida, J., La voix et le phénomène, op. cit., p. 89. 
pronunciada por un hablante expresa el estado de cosas de que llueve, y al mismo tiempo (en condiciones normales) señala a su auditorio la existencia de un estado mental accesible solo a él: la creencia de que llueve. Por el contrario, en el «discurso solitario» existen también las expresiones con significado, puesto que las palabras siguen significando lo mismo que significan cuando nos comunicamos con otros, pero el lenguaje ya no actúa como señal o como indicio de un estado mental que da sentido a las expresiones, puesto que el sujeto es perfectamente consciente de la existencia de sus propios estados mentales sin necesidad de inferirlos a partir de los signos: «en el discurso monológico las palabras no pueden servirnos para la función de señalar, notificar la existencia de actos psíquicos, pues semejante señal aquí sería inútil, ya que tales actos son vividos por nosotros en el mismo momento» ${ }^{20}$. Pero Husserl no se limita a afirmar que, en ese monólogo interior en que consiste el pensamiento, las palabras no funcionan como indicios o señales de vivencias psíquicas. Más allá de esto, parece inferir que los signos mismos no existen: «nos contentamos normalmente con palabras representadas, en vez de palabras reales. En nuestra fantasía se cierne un signo verbal hablado o escrito; pero en verdad este signo no existe ${ }^{21}$. Pues bien, Derrida objeta a Husserl que en el monólogo interior el signo no existe como signo efectivamente proferido o escrito que señaliza la existencia de actos psíquicos, pero sí como expresión, como signo que articula el discurso interior, el discurso de la conciencia.

Consideremos el resultado de esta argumentación. Hasta aquí Derrida no ha hecho otra cosa que tomar un punto de partida diferente para recorrer el camino trazado algunos años antes por la filosofía analítica, y de hecho los argumentos de Wittgenstein pueden servir para aclarar y confirmar las críticas de Derrida a la fenomenología de Husserl. En las Investigaciones filosóficas también Wittgenstein cuestiona el supuesto, típico de la filosofía de la conciencia, de una superposición del lenguaje sobre un sustrato de pensamiento prelingüístico, y afirma que el lenguaje es la condición misma del pensamiento: "Cuando pienso con el lenguaje, no me vienen a la mente "significados" además de la expresión verbal; sino que el lenguaje mismo es el vehículo del pensamiento» -leemos en el parágrafo 329. En consecuencia, en §504 Wittgenstein sostiene, al igual que Derrida, que el pensamiento no comunicado (el de la «vida solitaria del alma») tiene una articulación lingüística en la misma medida en que la tiene el pensamiento expresado en voz alta y comunicado a otros:

(...) Cuando alguien dice: «¿Cómo puedo saber lo que quiere decir [meint]? Al fin y al cabo, sólo veo sus signos», yo respondo: «¿Cómo puede saber él lo que quiere decir? Al fin y al cabo, tampoco él tiene otra cosa que sus signos».

Y en la misma línea, el §501 propone un experimento mental destinado a mostrar que no podemos referirnos intencionalmente a estados de cosas sin emplear signos:

20 Husserl, E., Investigaciones lógicas, vol. I, op. cit., p. 242.

21 Ibíd., p. 242, subrayado por mí. 
«La finalidad del lenguaje es expresar pensamientos» - Así pues, la finalidad de cada oración sería expresar un pensamiento. ¿Qué pensamiento expresa la oración «Llueve»?22.

La primera frase de esta cita, que aparece entrecomillada, representa la posición de Husserl, y su insostenibilidad se hace patente —según Wittgenstein- tan pronto como caemos en la cuenta de que no podemos concebir el pensamiento de que llueve sin pensar precisamente en la proposición «llueve». Quizás se objetará que el pensamiento prelingüístico correspondiente a la proposición «llueve» sería algo así como la imagen mental del agua cayendo, o la sensación imaginada de la humedad y el frío, etc. Pero recordemos que el propio Husserl insistía en que esa imagen mental concomitante (por no hablar de otras sensaciones subjetivas) no es el pensamiento significado con la proposición «llueve», como tampoco la imagen mental de Napoleón (a pie o a caballo, con sombrero o sin él, etc.) es el significado del nombre «Napoleón» ni el de la descripción "el vencedor de Jena». Así, incluso si Husserl tuviera razón al afirmar que el pensamiento, sea éste lo que sea, no se reduce a los signos lingüísticos (como tampoco se reduce a las imágenes de la fantasía), los partidarios del giro lingüístico podrían seguir teniendo razón al afirmar, por su parte, que no es posible pensar sin signos.

Pero las similitudes entre la crítica de Derrida a Husserl y la crítica analítica a la filosofía de la conciencia terminan aquí, pues si para Wittgenstein el lenguaje constituye nuestro pensamiento, en la filosofía de Derrida más bien parece desfondarlo. Peirce sostenía que es imposible pensar sin signos; Derrida suscribe esa tesis, pero le añade el paradójico complemento de que, en el fondo, también es imposible pensar con signos, porque los signos «dislocan»irremediablemente el pensamiento que, a la vez, hacen posible. ¿Qué argumentos apoyan esta extraña tesis de Derrida?

La dislocación generalizada de la experiencia mediada por signos (incluida la experiencia de uno mismo en la autoconciencia) es el resultado de llevar hasta sus últimas consecuencias la concepción estructuralista del lenguaje de Ferdinand de Saussure ${ }^{23}$. El Curso de lingüística general de Saussure se opone a

22 Wittgenstein, L., Investigaciones filosóficas, Crítica, Barcelona, 1988.

23 En la filosofía de Derrida, la experiencia también se disloca por otra vía: la de la temporalidad de la conciencia, que sin embargo nosotros desatenderemos aquí. Ambas vías están emparentadas para Derrida, porque el escalonamiento temporal de toda conciencia, que disgrega el presente en una estructura compleja de retenciones y protensiones, convierte la experiencia en algo similar al recuerdo o a la experiencia del otro, es decir, en algo comparable a las experiencias que hacemos mediante signos. Cf. sobre ambas perspectivas DERRIDA, J., "La Différance», en: Márgenes de la filosofía, op. cit. Contra esta interpretación de Husserl, el fenomenólogo Dan Zahavi niega que la teoría husserliana de la conciencia interna del tiempo 
lo que podemos llamar la concepción representacionista del signo (y del lenguaje en general) que ha sido predominante en la tradición filosófica ${ }^{24}$. De acuerdo con esta concepción, que se remonta al menos a Aristóteles, un signo es todo aquello que está en lugar de o en representación de otra cosa, pudiendo ser lo significado por el signo tanto un objeto del mundo como, a su vez, una representación mental de ese objeto ${ }^{25}$. Empleando un ejemplo relativamente sencillo, diríamos que el signo "caballo" puede referirse a un caballo o a la idea del caballo que nos formamos mentalmente. Saussure rechaza esta concepción representacionista del lenguaje con el argumento de que la relación entre lenguaje y mundo, entre el signo y lo designado, no puede concebirse de un modo tan simple, ya solo por el hecho de que nuestro pensamiento (incluido el que representa objetos externos a la conciencia) carece de todo orden, de toda articulación, cuando no está mediado por signos. Así, el Curso rebasa el campo de la Lingüística y asume compromisos filosóficos desde el principio, siendo el principal de ellos la tesis - que Saussure no demuestra, sino que más bien da por supuesta- de la mediación lingüística del pensamiento, es decir, la tesis fundamental del giro lingüístico:

Psicológicamente, y haciendo abstracción de su expresión por las palabras, nuestro pensamiento no es más que una masa amorfa e indistinta. Filósofos y lingüistas han coincidido siempre en reconocer que sin la ayuda de los signos seríamos incapaces de distinguir dos ideas de una forma clara y constante. Considerado en sí mismo, el pensamiento es como una nebulosa donde nada está delimitado necesariamente. No hay ideas preestablecidas, y nada es distinto antes de la aparición de la lengua ${ }^{26}$.

Este argumento de Saussure contra la concepción representacionista del lenguaje permite rechazar todas aquellas teorías referencialistas del significado que, tomando como paradigma los nombres propios, identifican el significado de las expresiones con sus objetos o referentes extralingüísticos ${ }^{27}$. Pero observemos que el argumento sirve también para rechazar las teorías intencionalistas, como la de Husserl: los «actos de significación» subjetivos no pueden ser el origen del significado de las expresiones si, por hipótesis, el pensamiento sin signos no es más que «una masa amorfa e indistinta» en la que no cabe identificar ni realizar actos mentales definidos. Y una vez despojados de

ponga en peligro la experiencia del presente, y niega también la asimilación de la experiencia temporal a la experiencia semiótica. Cf. Zahavi, D., Self-Awareness and Alterity, Northwestern UP, Evanston, 1999, p. 237, n. 94.

${ }_{24}$ Krämer, S., Sprache, Sprechakt, Kommunikation, Suhrkamp, Frankfurt, 2001, p. 21.

25 ARIstóteles, Sobre la interpretación, 16a. La relación entre el mundo, la mente y el lenguaje es, según Aristóteles, más o menos ésta: los objetos afectan nuestros órganos sensoriales y provocan una imagen mental, las palabras habladas representan esa imagen mental, y la palabra escrita representa, a su vez, a la palabra hablada.

26 Saussure, F. de, Curso de lingüística general, Akal, Madrid, 2002, p. 159.

27 Tugendhat denomina «objetualistas» (gegenstandstheoretisch) a estas teorías. Cf. TuGENDHAT, E., Vorlesungen zur Einführung in die sprachanalytische Philosophie, Suhrkamp, Frankfurt, 1976, p. 131 y sigs. 
la función de constituir el sentido, los sujetos quedan reducidos en la teoría de Saussure a la condición de meros vehículos de la lengua, entendida como un sistema de reglas independiente de los procesos de comunicación, o en la terminología saussureana: independiente del habla. Los hablantes se limitan a ejecutar unas reglas lingüísticas que por sí mismos son incapaces de establecer o modificar a voluntad, y de las que normalmente ni siquiera son conscientes: «la lengua no es una función del sujeto hablante, es el producto [social] que el individuo registra pasivamente; no supone jamás premeditación»; es la "parte social del lenguaje, exterior al individuo, que por sí solo no puede crearla ni modificarla $»^{28}$.

Ahora bien, si los signos no obtienen su significado de los objetos del mundo que representan, pero tampoco de los actos mentales de los hablantes que los emplean, ¿de dónde lo obtienen? ¿Cuál es el origen del significado? La respuesta de Saussure a esta pregunta es quizás la tesis más característica del pensamiento estructuralista, y no solo en lingüística. Podemos designarla como la tesis de la diferencialidad del significado y afirma que el significado se establece en el interior del sistema de la lengua, mediante la relación de cada signo con otros signos, y más en concreto, mediante relaciones de oposición y diferenciación entre signos. Los significados son relacionales, son "valores que emanan del sistema», "puramente diferenciales», y se definen "negativamente ${ }^{29}$. Un ejemplo del propio Saussure quizás pueda ayudarnos a captar esta idea, sin duda más fácil de formular que de comprender plenamente ${ }^{30}$. Los verbos «recelar», «temer» y «tener miedo» designan, según una concepción del significado quizás ingenua, diferentes actos o estados mentales emparentados entre sí pero no idénticos. Para Saussure, en cambio, el significado de cada una de estas palabras solo se establece por oposición a las restantes: «recelar» es quizás como «temer» pero con menos intensidad, o no con la certeza de que sea realmente peligroso aquello que (o de lo que) recelamos; «tener miedo» es quizás dejarse vencer por la angustia que despierta en nosotros aquello de lo que recelamos o que tememos, etc. Para Saussure, la prueba de que el significado es aquí puramente diferencial es el hecho de que, si uno de esos términos no existe en una lengua, «todo su contenido va a parar a sus rivales», es decir: los demás se lo reparten ${ }^{31}$. Y lo mismo puede decirse de todos los elementos de una estructura lingüística, tanto los asignificativos (como los fonemas, morfemas o lexemas) como los que tienen un significado completo. El significado no es, pues, sino el valor diferencial que cada elemento obtiene de sus relaciones de oposición con

28 Saussure, F. de, Curso de lingüística general, op. cit., p. 40, 41.

29 Ibíd., p. 165.

30 Aunque el ejemplo (en p. 164) se refiere a palabras, los lingüistas estructuralistas aplicaron en primer lugar a los fonemas estas ideas acerca del valor puramente diferencial. Cf. Trubetzkoy, N., «La fonología actual», en: Trubetzkoy, N., SAPIR, E. et al., Fonología y morfología, Paidós, Buenos Aires, 1972; Jakobson, R., Six leçons sur le son et le sens, Minuit, Paris, 1976.

31 Saussure, F. de, Curso de lingüística general, op. cit., p. 164. 
los restantes elementos de la lengua. De ahí la célebre sentencia de Saussure acerca del lenguaje: «en la lengua no hay más que diferencias» ${ }^{32}$.

Es fácil ver, sin embargo, que todas estas consideraciones de Saussure acerca del signo — el rechazo de la teoría referencialista del significado, la irrelevancia semántica de los hablantes, y la consiguiente tesis de la diferencialidad - conducen a una extraña clausura del lenguaje sobre sí mismo. Se diría que el lenguaje deja de ser un instrumento en manos de los hablantes, destinado a que éstos se comuniquen entre sí acerca de algo en el mundo, para convertirse en un enigmático mecanismo de autodiferenciación abstraído de todo proceso de comunicación e indiferente a los estados mentales de quienes parecían ser sus portadores naturales y únicos. Y lo cierto es que esta clausura parece haber preocupado a Saussure, que vacila un momento antes de rendirse definitivamente a su propia teoría. Así, una vez establecida su concepción diferencial del valor de los signos, Saussure se pregunta «en qué difiere este valor de lo que se denomina la significación», y señala la tensión que existe entre la concepción del significado como «contrapartida de la imagen auditiva» (es decir, del significante verbal) y como «contrapartida de los demás signos de la lengua» ${ }^{33}$. En este pasaje del Curso, Saussure se enfrenta a la disyuntiva entre una concepción referencial y otra diferencial del signo. Una disyuntiva que Saussure ilustra mediante la siguiente metáfora: el valor de una moneda de cinco francos puede establecerse especificando lo que podemos comprar con ella (por ejemplo, una determinada cantidad de pan), pero también especificando sus equivalentes monetarios (es decir, internos al sistema), como son cinco monedas de un franco, o una moneda de un dólar, etc. También los signos admiten esta doble perspectiva. Pueden cambiarse por una idea (un significado), pero también por otros signos (siempre diferentes del original, como sucede cuando compramos moneda extranjera, o con la calderilla que recibimos al cambiar un billete): «una palabra puede ser cambiada por alguna cosa desemejante: una idea; además, puede ser comparada con algo de igual naturaleza: otra palabra $»^{34}$. Pero es obvio que dar demasiada importancia a la concepción referencial del signo equivaldría a suscribir todavía la tradicional e ingenua concepción representacionista del lenguaje heredada de Aristóteles, y por eso no es extraño que Saussure se incline pronto por ignorar ese aspecto y acentuar el carácter relacional-diferencial del significado:

[El] valor [de una palabra] no está fijado (...) mientras nos limitemos a comprobar que puede ser "cambiada» por tal o cual concepto, es decir, que tiene tal o cual significación. Tenemos que compararla todavía con los valores similares, con las demás palabras que pueden oponérsele. (...) La parte conceptual del valor [es decir, el significado de los signos] está constituida

32 Ibíd. p. 168.

33 Ibíd., p. 162, 163.

34 Ibíd., p. 164. 
únicamente por las relaciones y las diferencias con los demás términos de la lengua ${ }^{35}$.

Pues bien, será Derrida quien extraiga todas las implicaciones de esta concepción. Según Derrida, la teoría de Saussure cancela el concepto mismo de signo, y junto con él, el de referente y el de sujeto. El concepto de signo en tanto que signo de algo, en tanto que representante de un objeto designado, queda suprimido desde el momento en que se asume sin ambigüedades la concepción relacional frente a la referencial. Si cada elemento de un sistema o estructura lingüística solo cobra su valor por sus relaciones de oposición o diferenciación frente a todos los demás, es evidente que los signos no mantienen ya ninguna conexión con nada externo a la estructura de la lengua. Así, llevar el estructuralismo de Saussure hasta el final implica

(...) rechazar incluso el concepto y la palabra signo. Pues la significación «signo» se ha comprendido y determinado siempre, en su sentido, como signo-de, significante que remite a un significado, significante diferente de su significado. Si se borra la diferencia radical entre significante y significado, es la palabra misma «significante» la que habría que abandonar $(\ldots)^{36}$.

Esta idea crucial requiere cierta aclaración. Si se afirma que el significado de los signos no es el objeto sino más bien el pensamiento del objeto, y se afirma que el pensamiento solo existe a su vez en la medida en que existen los signos que nos permiten articularlo, entonces los significados quedan absorbidos o integrados dentro del sistema de los significantes, y por tanto quedan también sometidos a las leyes semióticas que rigen para éstos, y en primer término a la tesis de la diferencialidad. Pero entonces ya no se ve en qué difieren los significantes de los significados. Derrida expresa esta conclusión diciendo que, para una teoría del lenguaje consecuentemente estructuralista, "todo significado se encuentra también en posición de significante» ${ }^{37}$. La noción misma de signo deja, pues, de tener sentido ${ }^{38}$.

35 Ibíd. p. 164, 166. Subrayado por mí. Saussure ilustra con algunas curiosas metáforas esta concepción del signo en las pp. 155 y 157: El expreso de las 8:45 no es un tren determinado, sino cualquier tren que salga precisamente a esa hora, por oposición a todos los que salen antes y después. Aunque todos sus edificios sean demolidos y reconstruidos de nuevo, una calle sigue siendo la misma calle en el callejero, porque su situación en relación con las otras calles permanece idéntica. Y una pieza de ajedrez solo cobra su función a partir de las reglas del juego, es decir, a partir de su relación con las otras piezas. En sí misma no existe como «pieza». Todo esto les ocurre también a las palabras en el sistema de la lengua.

36 Derrida, J., La escritura y la diferencia, Anthropos, Barcelona, 2012, p. 386.

37 DERridA, J., «Semiología y gramatología», en: Ideas y Valores, vol. 25, núm. 46 (1976), p. 55.

38 Cf. Derrida, J., Márgenes de la filosofía, op. cit., pp. 45 y sigs. De ahí que Derrida —en una de sus frecuentes y muy particulares decisiones terminológicas- prefiera reemplazarla por un concepto nuevo: el de «marca», que debemos entender como una paradójica variante del signo, algo así como un signo carente de exterioridad. Cf. DerRidA, J., «Semiología y gramatología», loc. cit., p. 60: «El juego de las diferencias supone síntesis y reenvíos que prohíben que bajo ningún sentido y en ningún momento un elemento simple sea presente en 
Quizás resulte tentador apelar en este punto al sentido común, e intentar salvar la distinción entre los signos y sus significados — distinción ésta que todavía Saussure mantenía inconsistentemente- recurriendo de nuevo a una teoría referencialista y apelando a los objetos mismos del mundo a los que parece remitir nuestro lenguaje. Al fin y al cabo, una cosa es la palabra «mesa» y otra cosa es una mesa. Pero para Derrida de nada serviría esta estrategia, porque la filosofía estructuralista del lenguaje relega los objetos ya desde el principio - es decir, ya en Saussure - a una posición exterior a la estructura, y por tanto irrelevante. La estructura lingüística debe pensarse como enteramente autorreferencial, y las cosas del mundo ocuparían a lo sumo la posición inaccesible de la cosa en sí kantiana. Las "cosas mismas» que todavía privilegiaba Husserl, y cuya experiencia directa debía servirnos para verificar las expresiones lingüísticas proporcionando así un criterio para nuestras pretensiones de conocimiento, solo pueden determinarse para nosotros — solo podemos pensarlas y referirnos a ellas - en la medida en que queden integradas en la trama de las relaciones diferenciales, o dicho de otro modo: en la medida en que pasen a ser ellas mismas elementos de la estructura y, por tanto, signos (o «huellas» $\mathrm{O}$ «marcas») ${ }^{39}$. Lo que no cabe admitir, desde un pensamiento estructuralista más consecuente que el de Saussure, es que las cosas mismas se hagan presentes a la conciencia en una experiencia incontaminada, libre de signos y, por tanto, ajena al torbellino que convierte los significados en significantes de otros significados que a su vez no son sino significantes ${ }^{40}$. Así lo afirma Derrida en un elocuente pasaje de la Gramatología:

Lo que inaugura el movimiento de la significación es lo que hace imposible su interrupción. La cosa misma es un signo. Proposición inaceptable para Husserl (...). No hay una fenomenalidad que reduzca el signo o el representante para dejar brillar, al fin, a la cosa significada en la luminosidad de su presencia. La denominada cosa misma es desde un comienzo un representamen sustraído a la simplicidad de la evidencia intuitiva ${ }^{41}$.

sí mismo y no remita sino a sí mismo. Ya sea en el orden del discurso hablado o del discurso escrito, ningún elemento puede funcionar como signo sin remitir a otro elemento que no es simplemente presente. (...) Lo único que existe, de parte a parte, son diferencias de diferencias y trazas de trazas». Cf. sobre esto Frank, M., Was ist Neostrukturalismus, Suhrkamp, Frankfurt, 1984, pp. 89-90.

39 Así en Derrida, J., «La Différance», en: Márgenes de la filosofía, op. cit., p. 46: «este principio de la diferencia, como condición de la significación, afecta a la totalidad del signo, es decir, a la vez a la cara del significado y a la cara del significante».

40 Dar a las «cosas mismas» alguna importancia en un pensamiento estructuralista equivale a lastrarlo con adherencias metafísicas. En este punto la semiología de Derrida conecta con la crítica heideggeriana de la «metafísica de la presencia», que Derrida desarrolla a su manera. Saussure todavía permanecería preso de esa metafísica. Cf. sobre esto DERRIDA, J., De la gramatología, op. cit., p. 53 y sigs.

${ }^{41}$ Derrida, J., De la gramatología, op. cit., p. 64. "Representamen» es el término que Peirce emplea para hablar de «signo». 
Pero la dislocación —o quizás sería mejor decir: la «deconstrucción»— de nuestra experiencia del mundo como efecto de su constitución lingüística o su entrelazamiento semiótico no estaría completa si Derrida no pusiera también en cuestión la noción del sujeto, del hablante que emplea los signos. Y también aquí Derrida puede limitarse a radicalizar las intuiciones fundamentales de Saussure: si para éste la lengua es un sistema o estructura de diferencias autosuficiente, e independiente de los sujetos que emplean los signos, Derrida extrae las últimas consecuencias de esta línea argumental que releva al sujeto de toda función en el proceso semiótico.

De nuevo una comparación con Wittgenstein puede servirnos para comprender este asunto. En principio, la afirmación de Saussure de que «la lengua no es una función del sujeto hablante», que «por sí solo no puede crearla ni modificarla $»^{42}$, converge con las ideas de Wittgenstein, quien propone algunos paradójicos experimentos mentales para apoyarlas. Así, en las Investigaciones filosóficas leemos lo siguiente:

Haz este experimento: $d i$ «Aquí hace frío» y pretende decir con ello [meine] «Aquí hace calor». ¿Lo puedes hacer? - ¿Y qué haces cuando lo haces? ¿Y hay sólo una manera de hacerlo? ${ }^{43}$.

Imagínate que alguien, con cara de dolor, señala su mejilla y dice: «iabracadabra!» - Le preguntamos "¿Qué quieres decir?», y él responde «Con ello quería decir [meinte] dolor de muelas». -Tú piensas en seguida: ¿Cómo puede 'querer decir dolor de muelas' con esta palabra? (... $)^{44}$.

La imposibilidad de fijar a voluntad el significado de las expresiones lingüísticas prueba que, sea cual sea la función semántica del sujeto hablante, en cualquier caso no es la que le atribuyen las teorías intencionalistas del significado $^{45}$. Pero a partir de aquí, la posición de Saussure difiere sustancialmente de las conclusiones que Wittgenstein extrae de estos experimentos. Especialmente el segundo de ellos muestra que la semántica intencionalista es insostenible porque choca con la objetividad que las convenciones lingüísticas acreditan de hecho en los procesos de comunicación entre hablantes, es decir, en el terreno de la pragmática del lenguaje. La identidad del significado de las expresiones es la condición de posibilidad de la comunicación, y por eso las reglas semánticas intersubjetivas, supraindividuales, trazan un límite a los intentos individuales de conferir significado a los signos. Pero Saussure no podía rechazar la semántica intencionalista apelando, como hace Wittgenstein, al fenómeno de la comunicación, puesto que Saussure, por razones metodológicas, se desentiende

42 Saussure, F. de, Curso de lingüística general, op. cit., p. 40, 41.

43 Wittgenstein, L., Investigaciones filosóficas, op. cit., §510.

44 Ibíd., $\$ 665$.

45 Esto se relaciona con el argumento de Wittgenstein contra los lenguajes privados. En un lenguaje tal el sujeto puede atribuir a los signos el significado que quiera, pero todo lenguaje privado es en realidad una traducción (cifrada) de un lenguaje público. Los significados públicos, convencionales, son en este sentido condición de posibilidad también de los significados privados. 
sistemáticamente de la pragmática, o en su terminología: del habla. La constitución de una teoría verdaderamente científica del lenguaje requiere, para Saussure, la renuncia a toda perspectiva diacrónica y a toda investigación de la pragmática, y exige atenerse estrictamente a un enfoque sincrónico y estructural del lenguaje. Por eso el Curso de Saussure no sólo descarta todos los enfoques metodológicos fundamentalmente históricos que habían predominado en la filología del siglo XIX, sino que también excluye la pragmática de la investigación propiamente lingüística:

(...) Sería quimérico reunir bajo un mismo punto de vista la lengua y el habla. (...) Tal es la primera bifurcación que se encuentra cuando uno pretende hacer la teoría del lenguaje. Hay que escoger entre dos caminos imposibles de seguir al mismo tiempo; deben seguirse por separado. En rigor se puede (...) hablar de una lingüística del habla. Pero no hay que confundirla con la lingüística propiamente dicha, cuyo único objeto es la lengua. Nosotros nos aplicaremos únicamente a esta última ${ }^{46}$.

Pero si se pone metódicamente entre paréntesis la pragmática del lenguaje, entonces la prueba de que la semántica intencionalista es falsa no puede hallarse observando lo que sucede en la comunicación, en el empleo de signos en el intercambio de actos de habla. Y por eso Saussure, y tras él todo el estructuralismo y postestructuralismo, no interpreta la constatación de que el sujeto no puede crear ni cambiar a voluntad los significados como una prueba de que existen convenciones semánticas intersubjetivas que se acreditan en la práctica lingüística, sino más bien como una prueba de que también el sujeto está atrapado, como un elemento pasivo, en las redes del lenguaje, en la estructura ilimitada de las diferenciaciones y oposiciones entre signos.

Esta idea - que ha tenido la rara fortuna de hacerse muy popular a pesar de lo extraña que resulta- admite al menos dos lecturas distintas. La primera de ellas ha pasado a formar parte de los tópicos del pensamiento postestructuralista, y viene a decir que la función del sujeto se limita a actualizar las reglas del sistema de la lengua, de manera que los sujetos somos solo los canalizadores o los vehículos pasivos de las estructuras y sus trasformaciones. A esto se refiere, por ejemplo, Claude Lévi-Strauss cuando, al final de Mitológicas, caracteriza el sujeto como «el lugar insustancial ofrecido a un pensamiento anónimo a fin de que allí se despliegue», y conmina a las ciencias humanas a desembarazarse por fin de ese «insoportable niño mimado que ocupó demasiado tiempo el escenario filosófico» ${ }^{47}$. Y algo muy similar afirma Michel Foucault en las celebérrimas páginas finales de Las palabras y las cosas, en las que el sujeto (o el hombre) se presenta como una figura transitoria, condenada por el estructuralismo a borrarse del pensamiento occidental «como en los límites del mar un rostro de arena» ${ }^{48}$.

46 Saussure, F. de, Curso de lingüística general, op. cit., p. 47.

47 Lévi-Strauss, C., Mitológicas, vol. 4, Siglo XXI, México, 2009, p. 565, 621.

48 Foucault, M., Las palabras y las cosas, Siglo XXI, Madrid, 1997, p. 375. 
La segunda interpretación es quizás más sofisticada (aunque también mucho más elusiva y difícil de probar, e incluso de formular con suficiente claridad). Es la que encontramos en Derrida, para quien la consideración del sujeto como un mero receptáculo o vehículo de un pensamiento anónimo permanece presa, a pesar de todo, de las erróneas dicotomías filosóficas que habrían presidido todo el pensamiento occidental — calificado por Derrida de «metafísico»-, y que seguirían vigentes en el estructuralismo de Saussure. Me refiero (entre otras) a la distinción entre el significante y el significado, entre el lenguaje y los objetos, o entre la estructura y lo que queda fuera de ella. Y es que, en efecto, hacer del sujeto el receptáculo pasivo de un lenguaje o un pensamiento anónimos implica situarlo fuera de la estructura, en un lugar externo a ésta, y por tanto inmunizarlo contra la tesis de la diferencialidad, aunque sea para atribuirle ya solo una función subsidiaria y modestísima (la de vehículo o recéptaculo del lenguaje) frente a la posición señorial que adquiría en las teorías intencionalistas del lenguaje (la de fundador de los significados). En cambio, la radicalización ultra-estructuralista de la concepción saussureana del lenguaje obligaría, más bien, a absorber también el sujeto en la estructura, a disolverlo en la red de las relaciones diferenciales, y a rechazar su subsistencia extra-semiótica por las mismas razones por las que antes nos veíamos obligados a rechazar el concepto de signo (la distinción entre significante y significado) e incluso el concepto de referente, las "cosas mismas» externas a la estructura. Si nos referimos al sujeto, nos referimos a algo que, como todo lo demás, solo puede definirse, cobrar sentido y existir para nosotros en la medida en que se someta al principio de determinación diferencial entre signos. Así alcanzamos la más paradójica consecuencia de la filosofía del lenguaje de Derrida: la estructura lingüística que nos permite referirnos al sujeto en general - y que permite a cada uno referirse a sí mismo en particular como portador autoconsciente de sus propios estados mentales- pulveriza el objeto designado en un torbellino de significantes relacionados diferencialmente entre sí. Al igual que los significados y los objetos, el sujeto solo puede ser un elemento diferencial de la estructura que nos permite mentarlo, es decir, un signo. Aunque algo críptico, un pasaje de la Gramatología resulta muy revelador a este respecto. La «emancipación del signo ${ }^{49}$ frente a las intenciones significantes de los hablantes convierte la lengua en un sistema semiótico autosuficiente y rigurosamente autorreferencial (en «escritura», en la terminología de Derrida). El rechazo saussureano de la semántica intencionalista queda conectado con la liquidación del referente y la «dislocación» del sujeto:

Tal vez se comprenda mejor (...) por qué dice Saussure que la lengua no es una función del sujeto hablante. (...) Constituyéndolo y dislocándolo simultáneamente, la escritura es distinta del sujeto, en cualquier sentido que se lo

49 DERridA, J., De la gramatología, op. cit., p. 89. 
entienda. Nunca podría pensarse bajo su categoría (...).Y la ausencia original del sujeto de la escritura es también la de la cosa o del referente ${ }^{50}$.

(III)

Cuando una teoría del lenguaje concluye que «la cosa misma es un signo», empezamos a pensar que algún aspecto del argumento está necesitado de aclaración; cuando concluye que también el sujeto es un signo o queda pulverizado en un torbellino de signos, podemos estar prácticamente seguros de que se ha deslizado un error en alguna parte. ¿Qué es lo que falla en el caso de Derrida? El problema no parece estar en la tesis de la mediación lingüística del pensamiento, que Derrida hace valer inteligentemente contra Husserl, sino más bien en una teoría del lenguaje que amenaza con malograr filosóficamente desde la raíz la variante estructuralista (y postestructuralista) del giro lingüístico.

Paul Ricoeur señaló ya muy pronto —en un ensayo de 1963 titulado «Estructura y hermenéutica» en el que discutía las tesis de El pensamiento salvaje, publicado por Lévi-Strauss un año antes- que, pese a los logros del método estructuralista en el campo de la lingüística y otras ciencias humanas, resultaba muy problemática la formulación de una filosofía estructuralista, si entendemos por tal la reflexión sobre el alcance y los límites de ese método ${ }^{51}$. Según Ricoeur, la reflexión sobre el método estructuralista no podía articularse, a su vez, en los términos del estructuralismo sin conducirnos a la paradoja de un lenguaje sin hablantes y un pensamiento sin sujeto pensante o un «kantismo sin sujeto trascendental», por decirlo con la conocida fórmula de la que LéviStrauss se apropiaría después contra el propio Ricoeur ${ }^{52}$. La réplica estructuralista se apresuró a despachar esta objeción de Ricoeur acusando a éste de pretender rehabilitar una filosofía de la conciencia definitivamente derrotada, o de limitarse a evocar los valores de un caduco «humanismo» contra los sobrios descubrimientos de unas ciencias humanas que habrían alcanzado por fin un estatuto verdaderamente científico. Pero esta réplica era injusta, porque al señalar la errónea autocomprensión del método estructuralista Ricoeur no se limitaba, como pretendía Lévi-Strauss, a lamentar «la pérdida de la persona

50 Ibíd. Cf. también Derrida, J., «La Différance», en: Márgenes de la filosofía, op. cit., p. 50: «el sujeto (identidad consigo mismo o en su momento conciencia de la identidad consigo mismo, conciencia de sí) está inscrito en la lengua, es "función" de la lengua»; DERRIDA, J., «Semiología y gramatología», loc. cit., p. 61: «No existe ningún sujeto que sea agente, autor y maestro de la diferancia y al cual ella pertenecería eventual y empíricamente. La subjetividad - como la objetividad- es un efecto de diferancia, un efecto inscrito en un sistema de diferancia»; y DerRIDA, J., La diseminación, Fundamentos, Madrid, 1975, p. 451: «La presencia nunca es presente».

51 Ricoeur, P., El conflicto de las interpretaciones, FCE, Buenos Aires, 2003, p. 46 y sigs.

52 Ibíd., 53. Cf. Lévi-Strauss, C., Mitológicas, vol. 1, FCE, México, 1968, p. 20. 
humana y de sus valores consagrados ${ }^{53}$, sino que ponía de manifiesto algunos problemas que afectan sobre todo a la filosofía estructuralista del lenguaje. Y es que las decisiones metodológicas que Saussure toma a fin de constituir una lingüística estructuralista —único medio, al parecer, de constituir una lingüística verdaderamente científica-incurrían desde el principio en un vicio teórico que algunos filósofos del lenguaje han llamado «falacia abstractiva (54, $^{54}$ y que consiste en estudiar el lenguaje prescindiendo enteramente de su dimensión pragmática, es decir, olvidando que el lenguaje es, entre otras cosas, un instrumento en manos de hablantes que pretenden comunicarse entre sí acerca de algo en el mundo. Y aunque seguramente no hay nada que objetar a las decisiones metodológicas de Saussure si de lo que se trata es de fundar una ciencia del lenguaje, los problemas empiezan cuando se construye toda una filosofía (es decir: una reflexión sobre el propio método estructuralista, una filosofía del lenguaje, un análisis de la relación de éste con la conciencia y la autoconciencia, una teoría del significado, etc.) sobre la base de esa exclusión de la pragmática. Más que reivindicar los rancios valores del humanismo, lo que afirmaba Ricoeur en aquel ensayo era que toda la filosofía estructuralista y postestructuralista quedaba inevitablemente lastrada por la falacia abstractiva de la lingüística saussureana.

Los problemas que genera la abstracción de la dimensión pragmática del lenguaje aparecen pronto: ya en la teoría saussureana del significado. Ya vimos que, tras rechazar las concepciones referencialistas e intencionalistas, para Saussure el significado ya solo puede emerger de relaciones de diferenciación y oposición internas al sistema de la lengua. Lo que Saussure cree obtener de este modo es una teoría del significado estrictamente objetivista, en la que los significados emergen como por si solos (casi diríamos: sin la ayuda de nadie) de las relaciones entre los significantes. Todos los estructuralistas posteriores comparten esta semántica objetivista, que explica lo que el lingüista Roman Jakobson llamaba el «misterio de la idea incorporada a la materia fónica ${ }^{55}$ - es decir, la enigmática emergencia del significado- a partir de las relaciones de oposición entre elementos carentes ellos mismos de significado. Para una epistemología de orientación positivista (como la que el estructuralismo hereda de Comte y Durkheim) $)^{56}$, un proceso semiótico anónimo, objetivo, despersonalizado, parece el único que conviene a una lingüística científica. Pero este objetivismo semántico resulta un tanto ingenuo (pese a la retórica cientificista con que los estructuralistas lo acompañan a menudo ${ }^{57}$ cuando reparamos

53 Lévi-Strauss, C., Mitológicas, vol. 4, op. cit., p. 576. En esta misma línea también argumenta PARdo, J. L., Estructuralismo y ciencias humanas, Akal, Madrid, 2001, cap. I.

54 Apel, K.-O., Auseinandersetzungen, Frankfurt, Suhrkamp, 1998, p. 100 y sigs.

55 JakoBson, R., Six leçons sur le son et le sens, op. cit., p. 22.

56 Cf. Harris, M., El desarrollo de la teoría antropológica, Siglo XXI, Madrid, 1985.

57 Lévi-Strauss, C., Mitológicas vol. 1, op. cit., p. 21: "Creemos que nada mejor que la mitología permite ilustrar y demostrar empíricamente la realidad de este pensamiento objetivado. (...) No pretendemos mostrar cómo piensan los hombres en los mitos, sino cómo 
en que la omisión de la subjetividad en la constitución del significado es solo aparente. Es verdad que las expresiones significativas de una lengua se forman mediante la combinación de elementos no significativos, como los fonemas, de acuerdo con reglas estrictas de las que como hablantes no somos conscientes. Por eso las combinaciones arbitrarias de fonemas o morfemas no dan como resultado expresiones de una lengua, mientras que las combinaciones de acuerdo con esas reglas generan expresiones posibles en esa lengua. Pero es evidente que todo este proceso presuntamente objetivo está presidido desde el comienzo por esa figura que los estructuralistas querrían excluir, o a lo sumo admitir solo en calidad de mero repetidor: el sujeto, el hablante ${ }^{58}$. Desde una posición afín a la hermenéutica de Ricoeur, Manfred Frank objeta al postestructuralismo que la noción e incluso el término mismo de «significante» implica ya la idea de significación, y esta idea sólo es inteligible en relación con un sujeto para el que los signos significan algo (o no significan nada): «En la definición del significante se incluye ya el predicado de la significancia; por tanto, es circular la afirmación de que lo segundo se obtiene de lo primero ${ }^{59}$. Si esta observación es correcta, resulta imposible pensar el significado de forma enteramente objetivista. Un signo que no es signo para nadie es también un signo que no significa nada, por más que cumpla formalmente las reglas de una lengua. La combinación de elementos de una estructura lingüística es condición necesaria para la formación de una expresión con significado, pero no es condición suficiente. Hace falta algo más, y ese algo más es la conciencia del hablante. Y observemos que, por las mismas razones por las que el significado no puede emerger sin el concurso del sujeto, es imposible disolver el sujeto en el juego de oposiciones de los significantes, pues éstos solo pueden significar sobre el trasfondo de la conciencia, que se convierte en una condición trascendental de posibilidad ya

los mitos se piensan en los hombres, sin que ellos lo noten. Y acaso (...) convenga llegar aún más lejos, prescindiendo de todo sujeto para considerar que, de cierta manera, los mitos se piensan entre ellos». También Mitológicas vol. 4, op. cit., p. 621: «el estructuralismo reintegra el hombre a la naturaleza». En su particular exposición del pensamiento de Lévi-Strauss, el poeta Octavio Paz subraya también este objetivismo en relación con el significado de los mitos: «las combinaciones de los mitemas deben producir mitos con la misma fatalidad y regularidad con que los fonemas producen sílabas, morfemas, palabras y textos», PAz, O., El nuevo festín de Esopo, Seix Barral, Barcelona, 2008, p. 29. La misma idea central constituye también el segundo de los "criterios» que G. Deleuze propone para reconocer el estructuralismo: «si los elementos simbólicos no tienen designación extrínseca ni significación intrínseca, sino únicamente un sentido de posición, ha de plantearse por principio que el sentido resulta siempre de la combinación de elementos que no son en sí mismos significantes», Deleuze, G., «¿En qué se reconoce el estructuralismo?», en: CHATELÊT, F., dir., Historia de la filosofía, Madrid, Espasa-Calpe, 1978. También PARDo, J. L., Estructuralismo y ciencias humanas, op. cit. cap. I, destaca este rasgo fundamental del estructuralismo.

58 El sujeto no puede ocupar siquiera la posición de espectador, pues esto implicaría una distancia del sujeto respecto del proceso semiótico que los estructuralistas más consecuentes (como Derrida) no podrían conceder.

59 Frank, M., Ansichten der Subjektivität, Suhrkamp, Berlin, 2012, p. 70. cf. también Frank, M., Selbstbewusstsein und Selbsterkenntnis, op. cit., p. 203. 
siempre supuesta en todo proceso semiótico. La propuesta de Derrida de disolver en el proceso semiótico también el sujeto que emplea los signos solo puede ya sonar como un inmenso error categorial, algo así como incluir en el inventario de las herramientas de un taller al operario que las emplea para su trabajo.

Y así como el significado solo se explica si se admite un sujeto, así también parece claro que solo acogiendo la subjetividad (el hablante) y la dimensión pragmática (el habla) parece posible comprender el contacto de los signos con el mundo y superar el cierre autorreferencial de las estructuras. Saussure toma como unidad mínima de significación la palabra, puesto que ésta es la primera entidad que cobra sentido en un sistema lingüístico a partir de elementos no significativos (fonemas, lexemas y morfemas) ${ }^{60}$. Pero las palabras por si solas no se refieren a nada, incluso aunque tengan un sentido virtual en el interior de una estructura. Desde Frege sabemos que, para referirse a algo, las palabras tienen que combinarse en proposiciones o enunciados (con la forma $\mathrm{S}$ es P), y que por tanto éstos son las unidades mínimas dotadas de una función referencial y un valor de verdad. Solo podemos referirnos a algo diciendo algo sobre ello, atribuyéndole alguna propiedad, es decir, enunciando una proposición que puede ser verdadera o falsa ${ }^{61}$. Referencia, predicación y enunciación son, pues, actos lingüísticos estrechamente ligados, porque ninguno de ellos puede realizarse sin realizar los otros dos. Ahora bien, tampoco aquí podemos prescindir de la subjetividad, porque todos estos actos lingüísticos ya no son anónimas operaciones virtuales internas a una estructura, sino actos efectivamente realizados por hablantes. De manera que explicar la referencia obliga a renunciar al anonimato y la abstracción de las estructuras sin hablantes y sin habla ${ }^{62}$. O por decirlo a la inversa: solo porque el estructuralismo abstrae artificialmente del lenguaje su dimensión pragmática puede creerse capaz de explicar el significado omitiendo la subjetividad de los hablantes, al tiempo que se vuelve incapaz de explicar la dimensión propiamente semántica de los signos, su referencia al mundo.

La «falacia abstractiva» de la lingüística saussureana conduce, pues, a una extraña filosofía de estructuras anónimas autorreferenciales y de cosas convertidas en signos. En una palabra: a la filosofía de Derrida. Se trata de una consecuencia inevitable si, por una decisión metodológica, se apuesta por un enfoque que reduce las principales propiedades del lenguaje a los escuetos términos de las relaciones diferenciales entre elementos asignificativos. Derrida tiene razón cuando afirma que su filosofía desarrolla «las exigencias

${ }^{60}$ Cf. Frank, M., «Sind Bewusstsein und Denken wesentlich sprachlich?», en: KeIL, G. y Tietz, U. (eds.), Phänomenologie und Sprachanalyse, Mentis, Padeborn, 2006, p. 44.

61 Ricoeur, P., El conflicto de las interpretaciones, op. cit., p. 82: «el momento de la trascendencia del signo (...) es contemporáneo de la oración». Ricoeur menciona expresamente a Frege en este contexto. Sobre esto cf. por ejemplo SchnäDelbach, H., Was Philosophen wissen, Beck, München, 2013, cap. 3.

62 Ricoeur, P., El conflicto de las interpretaciones, op. cit., p. 83: «el acto de habla se opone al anonimato del sistema». 
principales, más legítimas, del estructuralismo» ${ }^{63}$, y su propuesta de relevar la lingüística por una «gramatología» que subordina el habla, la subjetividad y la referencia a una archi-escritura que ya solo se atiene a la dinámica anónima de las oposiciones diferenciales puede interpretarse como una legítima heredera del programa inaugurado por el Curso de Saussure. Pero en lugar de seguir ese camino hasta el final, como hace Derrida, también cabe revisar el «modelo trunco ${ }^{64}$ del lenguaje que propone el estructuralismo, y no perder de vista que la objetividad y la ciencia no son lo mismo que el objetivismo y el cientificismo, y que el lenguaje es —entre otras cosas, pero también es esto- aquello que permite a cada uno comunicarse con otros sobre algo en el mundo.

Universidad de Zaragoza

José Luis López de Lizaga

lizaga@unizar.es

[Artículo aprobado para publicación en enero de 2018]

63 DERridA, J., «Semiología y gramatología», loc. cit., p. 61.

64 Ricoeur, P., El conflicto de las interpretaciones, op. cit., p. 236. 